\title{
Correction to: Finance Capital and the Time of the Novel or, Money Without Narrative Qualities
}

\author{
Mathias Nilges
}

\section{Correction to:}

Chapter 11 in: A. Falcato and A. Cardiello (eds.), Philosophy in the Condition of Modernism, https://doi.org/10.1007/978-3-319-77078-9_11

The original version of the book was published without acknowledging the original publisher in chapter 11 , which has now been added as article note. 